\title{
Schizophrenia as a disorder of disconnectivity
}

\author{
Andrea Schmitt • Alkomiet Hasan • \\ Oliver Gruber $\cdot$ Peter Falkai
}

Received: 20 June 2011 / Accepted: 1 August 2011/Published online: 25 August 2011

(C) The Author(s) 2011. This article is published with open access at Springerlink.com

\begin{abstract}
Schizophrenia is considered as a neurodevelopmental disorder with genetic and environmental factors playing a role. Animal models show that developmental hippocampal lesions are causing disconnectivity of the prefrontal cortex. Magnetic resonance imaging and postmortem investigations revealed deficits in the temporoprefrontal neuronal circuit. Decreased oligodendrocyte numbers and expression of oligodendrocyte genes and synaptic proteins may contribute to disturbances of microand macro-circuitry in the pathophysiology of the disease. Functional connectivity between cortical areas can be investigated with high temporal resolution using transcranial magnetic stimulation (TMS), electroencephalography (EEG), and magnetoencephalography (MEG). In this review, disconnectivity between different cortical areas in schizophrenia patients is described. The specificity and the neurobiological origin of these connectivity deficits and the relation to the symptom complex of schizophrenia and the glutamatergic and GABAergic system are discussed.
\end{abstract}

A. Schmitt $(\bowtie)$ · A. Hasan · O. Gruber · P. Falkai

Department of Psychiatry and Psychotherapy,

University of Göttingen, Von-Siebold-Str. 5,

37075 Göttingen, Germany

e-mail: aschmit@gwdg.de

\section{A. Schmitt}

Laboratory of Neuroscience (LIM27),

Institute of Psychiatry, University of Sao Paulo,

Rua Dr. Ovidio Pires de Campos 785, São Paulo,

SP 05453-010, Brazil
Keywords Schizophrenia - Connectivity - Magnetic resonance imaging - Transcranial magnetic stimulation . Magnetencephalography

\section{Introduction}

Schizophrenia is a severe psychiatric disorder with unknown etiology. Currently, a combination of genetic and environmental factors underlying the development of this disorder is discussed. Genetic association and genomewide association studies revealed several risk genes of schizophrenia, among them are neuregulin1, DISC1, D-amino-acid oxidase activator (DAOA/G72), zinc finger protein 804A (ZNF804A), transcription factor 4 (TCF4) [32]. Environmental factors such as obstetric complications with hypoxia [37], prenatal infection, season of birth, drug abuse, and migration [29] may interact with genetic factors, influencing onset and progression of the disease. This geneenvironmental interaction may comprise epigenetic alterations like DNA methylation and histone acetylation [35, 41]. An interaction between metabotropic glutamate receptor (GRM3) gene variants and severe obstetric complications on hippocampus volume has been reported, but this finding was not specific for schizophrenia [22]. Furthermore, it is assumed that these risk factors may affect brain tissue during perinatal neurodevelopment and may lead to the onset of psychotic symptoms in early adulthood during the synaptic pruning process of the prefrontal cortex [43]. In early adulthood, animal models of neonatal hippocampal lesions show behavioral deficits comparable to schizophrenia symptoms and reveal neurobiological deficits in the prefrontal cortex [17, 39], suggesting prefrontotemporal disconnectivity in the pathophysiology of the disease. 
MRI and post-mortem findings of disconnected circuits in schizophrenia

Meta-analyses of structural magnetic resonance imaging (sMRI) studies reveal gray matter volume deficits in different brain regions in schizophrenic patients. Affected regions are the medial temporal lobe including the hippocampus, the heteromodal association cortex including the prefrontal, anterior cingulate, superior temporal and parietal cortex as well as the thalamus. The degree of gray matter reduction is in the range of $5-10 \%$ in the frontotemporal and basal ganglia-thalamocortical network [10, $13,16]$.

Beside effects of environmental factors like cannabis abuse and trauma on cortical thickness in schizophrenia patients [19] or on reduced hippocampal volumes in patients and relatives with obstetric complications [8], schizophrenia susceptibility genes like neuregulin1 variants have shown impact on hippocampus volume [18], white matter density, and integrity in the anterior limb of the internal capsule [30]. A ZNF804A risk variant was associated with reduced cortical gray matter thickness in several regions [42].

sMRI and postmortem schizophrenia studies have shown volume loss in the medial temporal lobe, especially in the hippocampus, as one of the most consistent structural abnormalities [1]. A meta-analysis of diffusion tensor imaging (DTI) studies shows reductions in the myelin membranes and decreased white matter anisotropy in the deep left prefrontal and temporal cortex in schizophrenia and supports the hypothesis of structural and functional disconnectivity [9]. Neuronal axons traversing the limbic pathways from the hippocampus are connected to prefrontal cortex, anterior cingulate cortex, and thalamus. These pathways are involved in higher cognition and information processing, domains in which schizophrenia patients exhibit severe deficits [12].

A variety of functional MRI (fMRI) studies revealed disturbed connectivity in complex hippoampal, prefrontal and cerebellar-thalamic-prefrontal networks in schizophrenia [31]. In patients and non-psychotic subjects at increased risk dynamic causal modeling in fMRI studies revealed decreased effective connectivity between the posterior hippocampus and prefrontal cortex during working memory tasks [3, 23]. According to these results, postmortem studies revealed a loss of myelin-building oligodendrocytes in prefrontal and hippocampal subregions, leading to impaired nerve cell propagation of information $[24,36]$. Furthermore, gene expression of oligodendrocyterelated genes is decreased in schizophrenia. An additional synaptopathy with decreased expression of glutamatergic and gamma-amino-butyric acid (GABA)ergic synaptic proteins and consecutive disturbance of microconnectivity
[7, 25] is completing the complex framework of disconnectivity in schizophrenia.

\section{Neurophysiological investigations of cortical disconnectivity in schizophrenia}

Transcranial magnetic stimulation (TMS)

In schizophrenia patients, alterations of intracortical and intercortical connectivities at subsecond timescales were investigated by TMS (see Fig. 1) and these impaired connectivities have been linked to an abnormal cerebral lateralization and a cerebral asymmetry in schizophrenia patients.

The inhibitory connection between both primary motor cortices (M1), which is discussed to be mediated by corpus callosum pathways, was found to be deficient in schizophrenia patients [5]. One further study supported the idea of an altered interhemispheric connection, revealing a selectively impaired facilitatory connectivity between the left dorsal premotor cortex and the right M1 [34]. As a third disrupted interhemispheric pathway, the connection between right cerebellum and left M1 was shown to be deficient in schizophrenia patients [6], indicating a disrupted direct cerebellar-M1 connection or an abnormal

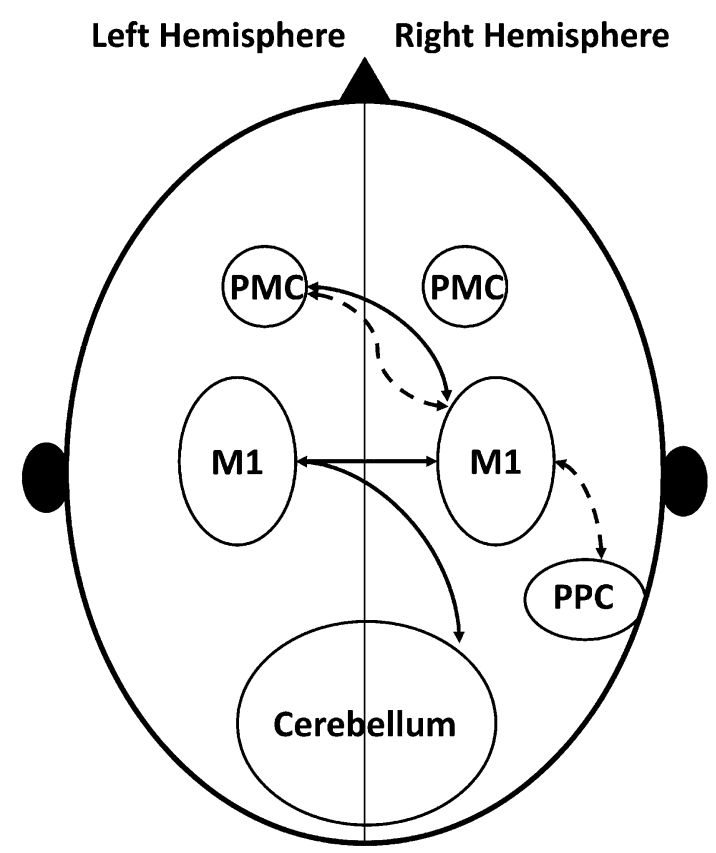

Fig. 1 Schematic presentation of connectivities between different cortical areas evaluated by TMS in schizophrenia patients. The inhibitory connectivity between left premotor areas and the right primary motor cortex is not affected, whereas the facilitatory connectivity between these two areas is reduced. PMC Premotor cortex, M1 Primary motor cortex, PPC Posterior parietal cortex, Dashed line facilitatory connectivity, Solid line inhibitory connectivity 
cerebellar inhibitory output. A disturbed intrahemispheric connectivity between the right posterior parietal cortex (PPC) and the right M1 in schizophrenia patients has been reported, too [28]. Finally, a dysfunctional interhemispheric connection between the right premotor and left M1 was discovered with a plasticity inducting repetitive TMS [33].

\section{EEG/MEG}

EEG and MEG provide insight into cortical rhythms and neuronal oscillations. In general, synchronous cortical rhythms support the idea of intact functional and anatomical connection between different brain areas [4]. This is of particular importance as disturbed oscillatory activity, alterations in synchronization and dysfunctional intra- and interhemispheric connectivities are an important feature in schizophrenia [40].

Quantitative analysis of resting EEG recordings displayed an increased delta and/or theta activity, a decreased main frequency, a low mean alpha frequency ("hypofrontality") and an increased beta activity in schizophrenia patients $[15,26]$. In dependence of the type of measure (steady-state evoked potentials, amplitudes, induced oscillations, and resting state [40]), amplitudes and phases have been found to be abnormal in schizophrenia patients. A common pattern of the different brain oscillations in schizophrenia patients is a reduction in amplitude and altered phase synchronization in all frequency bands (with emphasis on the beta and gamma band activity) at rest, during sensory processing and cognitive tasks [38, 40]. Further evidence is provided by animal studies showing that the synchronization of brain oscillations depends on cortico-cortical connections within and between hemispheres $[11,40]$. Therefore, the findings of impaired neural oscillation and the reduced phase synchronization in schizophrenia patients can be considered as a marker for a functional disconnectivity between different brain areas and for dysfunctional cortical networks [40].

\section{Connectivity and neurotransmitter systems}

Insights to disturbed connectivity in schizophrenia have been provided by MRI, postmortem, and animal studies. Alterations in GABAergic and n-methyl-D-aspartate receptor (NMDAR)-mediated transmission display a common neurobiological background of connectivity deficits revealed by TMS/EEG/MEG. First, studies on human brain tissues showed lower GABA-related transcripts in four cortical areas in schizophrenia patients [21]. Second, the results of different TMS-studies using specific paradigms to investigate inhibitory intracortical networks point toward a GABAergic dysfunction in the motor system of this patient group [44]. Third, schizophrenia patients show a reduction in the mRNA expression of the GABA-synthesizing enzyme, GAD67, and a reduction in GABAergic interneurons in several cortical areas [2, 27].

These abnormalities in GABAergic transmission appear to be associated with NMDAR dysfunction and dysfunctional NMDAR, in turn, causes abnormal neuronal plasticity, which is thought to be a crucial pathophysiological process in schizophrenia patients [38]. A theory about abnormal synaptic plasticity from Stephan, Friston and Frith discussed the relationship between dysfunctional NMDAR and disconnectivity in schizophrenia patients [38]. In their theory, the underlying biological and pathophysiological agent of schizophrenia is a dysfunction of NMDAR with a consecutive reduced synaptic and cellular plasticity. This would affect long-range connections in the developing brain, induce abnormalities in different neurotransmitter systems (dopamine, serotonine, acetylcholine, GABA), lead to aberrant corollary discharge and to impaired perceptual interference. This theory and other theories, discussing the glutamate-hypothesis of schizophrenia, are supported by several lines of evidence. A reduced LTP-like focal, spike-timing-dependent-like synaptic plasticity and a reduced LTP-like non-focal, cortical plasticity are recent neurophysiological findings in schizophrenia patients $[14,20]$. Taken together, this may indicate dysfunctional NMDARs and a reduced signal-tonoise ratio with consecutive dysfunctional information processing [20]. Additionally, numerous studies display a link between NMDAR dysfunction and affected cortical oscillations and mismatched negativity deficits [40].

In summary, different neurophysiological, imaging, neuropathological and molecular biology methods have revealed a disconnectivity in schizophrenia patients - the underlying pathobiology still needs clarification, but alterations in the GABAergic and glutamatergic, NMDARmediated neurotransmissions might be possible candidates.

Conflict of interest A. Schmitt declares that she has no conflict of interest. A. Hasan been invited to scientific congresses by AstraZeneca and Lundbeck. O. Gruber was honorary speaker for the following companies: AstraZeneca, Bristol Myers Squibb, JanssenCilag, Lilly, Otsuka. O. Gruber has been invited to scientific congresses by AstraZeneca, Janssen-Cilag, Pfizer. P. Falkai was honorary speaker for Janssen-Cilag, AstraZeneca, Lilly, BMS, Lundbeck, Pfizer, Bayer Vital, SKB, Wyeth, Essex and during the last 2 years, but not presently, he was member of the advisory boards of JanssenCilag, AstraZeneca, Lilly and Lundbeck.

This supplement was not sponsored by outside commercial interests. It was funded by the German Association for Psychiatry and Psychotherapy (DGPPN).

Open Access This article is distributed under the terms of the Creative Commons Attribution Noncommercial License which permits any noncommercial use, distribution, and reproduction in any medium, provided the original author(s) and source are credited. 


\section{References}

1. Adriano F, Caltagirone C, Spalletta G (2011) Hippocampal volume reduction in first-episode and chronic schizophrenia: a review and meta-analysis. Neuroscientist [Epub ahead of print]

2. Benes FM (1998) Model generation and testing to probe neural circuitry in the cingulate cortex of postmortem schizophrenic brain. Schizophr Bull 24:219-230

3. Benetti S, Mechelli A, Picchioni M, Broome M, Williams S, McGuire P (2009) Functional integration between the posterior hippocampus and prefrontal cortex is impaired in both first episode schizophrenia and the at risk mental state. Brain 132:24262436

4. Buzsaki G, Draguhn A (2004) Neuronal oscillations in cortical networks. Science 304:1926-1929

5. Daskalakis ZJ, Christensen BK, Chen R, Fitzgerald PB, Zipursky RB, Kapur S (2002) Evidence for impaired cortical inhibition in schizophrenia using transcranial magnetic stimulation. Arch Gen Psychiatry 59:347-354

6. Daskalakis ZJ, Christensen BK, Fitzgerald PB, Fountain SI, Chen R (2005) Reduced cerebellar inhibition in schizophrenia: a preliminary study. Am J Psychiatry 162:1203-1205

7. Eastwood SL, Harrison PJ (2005) Decreased expression of vesicular glutamate transporter 1 and complexin II mRNAs in schizophrenia: further evidence for a synaptic pathology affecting glutamate neurons. Schizophr Res 73:159-172

8. Ebner F, Tepest R, Dani I, Pfeiffer U, Schulze TG, Rietschel M, Maier W, Traber F, Block W, Schild HH, Wagner M, Steinmetz H, Gaebel W, Honer WG, Schneider-Axmann T, Falkai P (2008) The hippocampus in families with schizophrenia in relation to obstetric complications. Schizophr Res 104:71-78

9. Ellison-Wright I, Bullmore E (2009) Meta-analysis of diffusion tensor imaging studies in schizophrenia. Schizophr Res 108:3-10

10. Ellison-Wright I, Glahn DC, Laird AR, Thelen SM, Bullmore E (2008) The anatomy of first-episode and chronic schizophrenia: an anatomical likelihood estimation meta-analysis. Am J Psychiatry $165: 1015-1023$

11. Engel A, Konig P, Kreiter A, Singer W (1991) Interhemispheric synchronization of oscillatory neuronal responses in cat visual cortex. Science 252:1177-1179

12. Fanselow MS, Dong HW (2010) Are the dorsal and ventral hippocampus functionally distinct structures? Neuron 65:7-19

13. Fornito A, Yucel M, Patti J, Wood SJ, Pantelis C (2009) Mapping grey matter reductions in schizophrenia: an anatomical likelihood estimation analysis of voxel-based morphometry studies. Schizophr Res 108:104-113

14. Frantseva MV, Fitzgerald PB, Chen R, Moller B, Daigle M, Daskalakis ZJ (2008) Evidence for impaired long-term potentiation in schizophrenia and its relationship to motor skill learning. Cereb Cortex 18:990-996

15. Gattaz WF, Mayer S, Ziegler P, Platz M, Gasser T (1992) Hypofrontality on topographic EEG in schizophrenia. Correlations with neuropsychological and psychopathological parameters. Eur Arch Psychiatry Clin Neurosci 241:328-332

16. Glahn DC, Laird AR, Ellison-Wright I, Thelen SM, Robinson JL, Lancaster JL, Bullmore E, Fox PT (2008) Meta-analysis of gray matter anomalies in schizophrenia: application of anatomic likelihood estimation and network analysis. Biol Psychiatry 64:774-781

17. Gruber AJ, Calhoon GG, Shusterman I, Schoenbaum G, Roesch MR, O'Donnell P (2010) More is less: a disinhibited prefrontal cortex impairs cognitive flexibility. J Neurosci 30:17102-17110

18. Gruber O, Falkai P, Schneider-Axmann T, Schwab SG, Wagner M, Maier W (2008) Neuregulin-1 haplotype HAP(ICE) is associated with lower hippocampal volumes in schizophrenic patients and in non-affected family members. J Psychiatr Res 43:1-6
19. Habets P, Marcelis M, Gronenschild E, Drukker M, van Os J (2011) Reduced cortical thickness as an outcome of differential sensitivity to environmental risks in schizophrenia. Biol Psychiatry 69:487-494

20. Hasan A, Nitsche MA, Rein B, Schneider-Axmann T, Guse B, Gruber O, Falkai P, Wobrock T (2011) Dysfunctional longterm potentiation-like plasticity in schizophrenia revealed by transcranial direct current stimulation. Behav Brain Res 224: $15-22$

21. Hashimoto T, Bazmi HH, Mirnics K, Wu Q, Sampson AR, Lewis DA (2008) Conserved regional patterns of GABA-related transcript expression in the neocortex of subjects with schizophrenia. Am J Psychiatry 165:479-489

22. Haukvik UK, Saetre P, McNeil T, Bjerkan PS, Andreassen OA, Werge T, Jonsson EG, Agartz I (2010) An exploratory model for $\mathrm{G} \times \mathrm{E}$ interaction on hippocampal volume in schizophrenia; obstetric complications and hypoxia-related genes. Prog Neuropsychopharmacol Biol Psychiatry 34:1259-1265

23. Henseler I, Falkai P, Gruber O (2010) Disturbed functional connectivity within brain networks subserving domain-specific subcomponents of working memory in schizophrenia: relation to performance and clinical symptoms. J Psychiatr Res 44:364-372

24. Hof PR, Haroutunian V, Friedrich VL Jr, Byne W, Buitron C, Perl DP, Davis KL (2003) Loss and altered spatial distribution of oligodendrocytes in the superior frontal gyrus in schizophrenia. Biol Psychiatry 53:1075-1085

25. Honer WG, Falkai P, Bayer TA, Xie J, Hu L, Li HY, Arango V, Mann JJ, Dwork AJ, Trimble WS (2002) Abnormalities of SNARE mechanism proteins in anterior frontal cortex in severe mental illness. Cereb Cortex 12:349-356

26. Hughes JR, John ER (1999) Conventional and quantitative electroencephalography in psychiatry. J Neuropsychiatry Clin Neurosci 11:190-208

27. Knable MB, Barci BM, Bartko JJ, Webster MJ, Torrey EF (2002) Molecular abnormalities in the major psychiatric illnesses: Classification and Regression Tree (CRT) analysis of post-mortem prefrontal markers. Mol Psychiatry 7:392-404

28. Koch G, Ribolsi M, Mori F, Sacchetti L, Codeca C, Rubino IA, Siracusano A, Bernardi G, Centonze D (2008) Connectivity between posterior parietal cortex and ipsilateral motor cortex is altered in schizophrenia. Biol Psychiatry 64:815-819

29. McGrath JJ, Murray RM (2011) Environmental risk factors for schizophrenia. In: Weinberger DR, Harrison PJ (eds) Schizophrenia, 3rd edn. Wiley-Blackwell, Oxford, pp 226-244

30. McIntosh AM, Moorhead TW, Job D, Lymer GK, Munoz Maniega S, McKirdy J, Sussmann JE, Baig BJ, Bastin ME, Porteous D, Evans KL, Johnstone EC, Lawrie SM, Hall J (2008) The effects of a neuregulin 1 variant on white matter density and integrity. Mol Psychiatry 13:1054-1059

31. Meyer-Lindenberg A, Bullmore T (2011) Functional brain imaging in schizophrenia. In: Weinberger DR, Harrison PJ (eds) Schizophrenia, 3rd edn. Wiley-Blackwell, Oxford, pp 353-371

32. O'Donovan MC, Owen MJ (2011) Genetic association in schizophrenia. In: Weinberger DR, Harrison PJ (eds) Schizophrenia, 3rd edn. Wiley-Blackwell, Oxford, pp 269-288

33. Oxley T, Fitzgerald PB, Brown TL, de Castella A, Daskalakis ZJ, Kulkarni J (2004) Repetitive transcranial magnetic stimulation reveals abnormal plastic response to premotor cortex stimulation in schizophrenia. Biol Psychiatry 56:628-633

34. Ribolsi M, Mori F, Magni V, Codeca C, Kusayanagi H, Monteleone F, Rubino IA, Siracusano A, Bernardi G, Centonze D, Koch G (2011) Impaired inter-hemispheric facilitatory connectivity in schizophrenia. Clin Neurophysiol 122:512-517

35. Sananbenesi F, Fischer A (2009) The epigenetic bottleneck of neurodegenerative and psychiatric diseases. Biol Chem 390:1145-1153 
36. Schmitt A, Steyskal C, Bernstein HG, Schneider-Axmann T, Parlapani E, Schaeffer EL, Gattaz WF, Bogerts B, Schmitz C, Falkai P (2009) Stereologic investigation of the posterior part of the hippocampus in schizophrenia. Acta Neuropathol 117:395-407

37. Sommer JU, Schmitt A, Heck M, Schaeffer EL, Fendt M, Zink M, Nieselt K, Symons S, Petroianu G, Lex A, Herrera-Marschitz M, Spanagel R, Falkai P, Gebicke-Haerter PJ (2010) Differential expression of presynaptic genes in a rat model of postnatal hypoxia: relevance to schizophrenia. Eur Arch Psychiatry Clin Neurosci 260(Suppl 2):S81-S89

38. Stephan KE, Friston KJ, Frith CD (2009) Dysconnection in schizophrenia: from abnormal synaptic plasticity to failures of self-monitoring. Schizophr Bull 35:509-527

39. Tseng KY, Lewis BL, Hashimoto T, Sesack SR, Kloc M, Lewis DA, O’Donnell P (2008) A neonatal ventral hippocampal lesion causes functional deficits in adult prefrontal cortical interneurons. J Neurosci 28:12691-12699
40. Uhlhaas PJ, Singer W (2010) Abnormal neural oscillations and synchrony in schizophrenia. Nat Rev Neurosci 11:100-113

41. van Os J, Rutten BP, Poulton R (2008) Gene-environment interactions in schizophrenia: review of epidemiological findings and future directions. Schizophr Bull 34:1066-1082

42. Voineskos AN, Lerch JP, Felsky D, Tiwari A, Rajji TK, Miranda D, Lobaugh NJ, Pollock BG, Mulsant BH, Kennedy JL (2011) The ZNF804A gene: characterization of a novel neural risk mechanism for the major psychoses. Neuropsychopharmacology 36:1871-1878

43. Weinberger DR (1996) On the plausibility of "the neurodevelopmental hypothesis" of schizophrenia. Neuropsychopharmacology 14:1S-11S

44. Wobrock T, Schneider M, Kadovic D, Schneider-Axmann T, Ecker UK, Retz W, Rosler M, Falkai P (2008) Reduced cortical inhibition in first-episode schizophrenia. Schizophr Res 105:252261 